\title{
Una nación fragmentada y una cultura que irrumpe
}

\section{A Fragmented Nation and a Culture that Bursts in Uma nação fragmentada e uma cultura que irrompe}

Mía Gallegos

Recibido: 10/7/2015 Aceptado: 30/10/2015 / http://dx.doi.org/10.15359/tdna.32-59.1

Creo que ese es el drama profundo de este país: está longitudinalmente cortado de pies a cabeza por la división ideológica y política. Este no es un país.

Carmen González Huguet

\section{Resumen}

Se realiza un análisis de la obra de González-Huguet, de Jimmy Hendrix toca mientras cae la lluvia, para proponer que el Estado y la cultura se orientan de manera diversa e irreconciliable y en qué sentido ambas nociones se distancian. El ensayo se posiciona en el caso de El Salvador.

Palabras clave: Cultura latinoamericana, Estado en América Latina, Carmen González-Huguet, El Salvador.

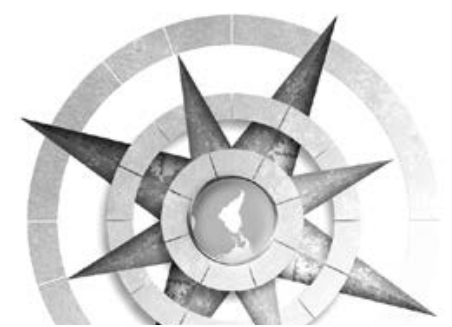

\section{Abstract}

An analysis of the work of Gonzalez-Huguet, Jimmy Hendrix toca mientras cae la lluvia, suggests that "State" and "culture" are oriented in very different, irreconcilable directions and describes in what way the two concepts differ. The essay focuses on the case of $\mathrm{El}$ Salvador.

Keywords: Latin American Culture, State, Carmen González-Huguet, El Salvador

\section{Resumo}

Este artigo é um análise do obra Jimmy Hendrix toca mientras cae la lluvia [Jimmy Hendrix tocou durante a chuva cai] peça escrita pela autora salvadorenha Carmen González-Huguet. Ele propõe que o Estado ea cultura são orientadas de modo diverso e irreconciliáveis e que os dois conceitos estão 
distanciados. $\mathrm{O}$ ensaio centra-se sobre o caso de El Salvador.

Palavras chave: Cultura Latino-Americana, Estado, Carmen González-Huguet, El Salvador

Estas palabras pertenecen a Carmen González-Huguet, autora que ha recibido numerosos reconocimientos por su labor literaria y es hoy una de las figuras más descollantes de la literatura de ese país y de Centroamérica. Las he colocado al principio porque me ocupo en este ensayo del análisis de una de sus obras más sobresalientes.

Una hipótesis me sobrevino de inmediato a la hora de escribir sobre el monólogo teatral de esta escritora: el Estado y la cultura se orientan de manera diversa e irreconciliable.

En el transcurso de este ensayo trataré de argumentar en qué sentido ambas nociones se distancian y si en un país como El Salvador actual es posible que confluyan la cultura y el Estado y, en términos más extendidos, la nación.

La obra escogida lleva el título de Jimmy Hendrix toca mientras cae la lluvia. Se trata de un monólogo teatral, que en sus inicios fue un cuento que González Huguet escribió y que se publicó en la Antología de
Cuentos Centroamericanos, edición a cargo del nicaragüense Sergio Ramírez Mercado.

El monólogo teatral que me propongo analizar se ha presentado en dos ocasiones en El Salvador. Su creadora lo publicó en el año 2004; no obstante, fue escrito entre el 2002 y el 2003.

El personaje central es una mujer común y corriente, una entre cientos de salvadoreñas a quienes les correspondió sobrevivir en el cruento período de la guerra civil que vivió El Salvador entre 1981 y 1992.

La mujer monologa y cuenta su vida: el despertar de la sexualidad, su embarazo, las escenas de guerra en zonas urbanas de El Salvador, su desclasamiento y posteriormente su condición de migrante en la ciudad de Los Ángeles en los Estados Unidos de América.

La mujer que habla, y digo literalmente habla porque la obra es de una fuerte oralidad, lo hace con los modismos propios de esa nación centroamericana y siempre le está contando su historia a la hija, quien en ningún momento habla $y$, si lo hace, ese "diálogo" necesariamente debemos construirlo los lectores. La mujer no tiene nombre, quizás

14 Una nación fragmentada y una cultura que irrumpe Mía Gallegos

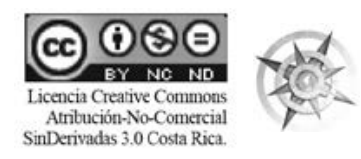


porque en gran medida representa a todas las mujeres y es así como se convierte en un símbolo de pueblo y de sobrevivencia.

Un análisis desde el punto de vista literario permite observar diferentes planos. El primero de ellos es el ya enunciado: una mujer joven, de la clase trabajadora descubre el amor y la sexualidad con su novio, finalmente tiene relaciones eróticas con él y esa tarde lluviosa, cuando salen de un hotelito, se enfrentan a una revuelta en las calles. Los militares arremeten y el novio de la joven recibe un disparo y muere en el acto.

Respecto del personaje central, González-Huguet señala que

...traté de que el habla del personaje fuera lo más apegada posible a nuestra realidad salvadoreña y al machismo de las mujeres salvadoreñas, que lo somos, y mucho. Quise que el vocabulario, en general, fuera el de uso común en cualquier ciudad de El Salvador y que todo: el marco de valores, el imaginario, los refranes y dichos, la manera de contar, las digresiones... todo respondiera a esa misma realidad, reflejándola con toda la fidelidad que pude. Además, hay guiños al lector avezado. (Entrevista realizada a la autora, junio 2015)
Cabe resaltar que, en esta obra, Carmen González Huguet transgrede el tabú de la sexualidad. Desde el inicio, el texto se abre con párrafos como el siguiente:

Él me metió la mano y yo de inmediato me quise morir cuando sentí bajo las yemas de mis dedos aquel calor húmedo, de animal en carne viva, que tenía un pellejo móvil y delgadito, muy blando, como el de la cabeza de una tortuga de tierra, que en aquel momento palpitaba debajo de mis dedos. (González Huguet, 2004: pág. 8)

Es imprescindible destacar aquí que el personaje femenino al contar su historia no intelectualiza la vivencia, se trata, pues de una mujer con escasa escolaridad que no reprime su emoción y su descubrimiento del sexo. Pero, además, al discurrir libremente y hablar sin represión, nos obliga como lectores a ver la realidad más allá de la fría razón. El texto está colmado de digresiones y eso nos permite entrar en la psique personal de la protagonista.

Mas aquí aparece un plano que es necesario analizar, ya que se utiliza desde el mismo título del monólogo teatral. Me refiero al músico Jimmy Hendrix y a la influencia de la contracultura estadounidense en esta obra de la salvadoreña. 
Todos los planos que aparecen en esta obra incitan e invitan a la transgresión. Más allá del hecho de que la autora cite al cantante norteamericano, hay en esta escogencia una particular referencia a las luchas estudiantiles que tuvieron lugar en ese país a finales de la década de los sesenta, en Berkeley, y en otros estados norteamericanos. La referencia a Woodstock es una constante, así como el consumo de marihuana que se inicia justamente en este período.

La juventud salvadoreña de los años sesenta y setenta recibe, también, el influjo contestatario de quienes se rebelan contra la guerra de Vietnam y la política de la nación del norte en relación con otros pueblos.

De ahí que la presencia de Jimmy Hendrix representa también una ruptura con los moldes convencionales, no representa a los Estados Unidos del poder político y económico. Mas no hay que olvidar a un personaje, el novio de la protagonista, quien es descrito como un mulato y en ese sentido se hermana con la figura del cantante estadounidense. Jimmy Hendrix es el ídolo, de manera que el joven mulato, novio de la protagonista, se convierte en un doble de Hendrix.
También la escogencia de la contracultura ocurre en un momento de vacío cultural. No se puede "sentir" ni experimentar una nación al filo de la guerra y con toda la complejidad política y militar de ese período. Más bien, aquí podría caber la noción de hibridez que, por otra parte, ya va siendo común en El Salvador, debido a la gran cantidad de migrantes que se han marchado, en especial a los Estados Unidos. Sin duda, esa mezcla del español con el inglés, en su fórmula spanglish, va convirtiéndose en un proceso de hibridación, tal y como lo explica Néstor García Canclini cuando dice lo siguiente:

Los procesos globalizadores acentúan la interculturalidad moderna al crear mercados mundiales de bienes materiales y dinero, mensajes y migrantes. Los flujos e interacción que ocurren en estos procesos han disminuido las fronteras y aduanas, así como la autonomía de las tradiciones locales y propician más formas de hibridación productiva, comunicacional y en los estilos de consumo que en el pasado. (2010: pág. 23)

En la obra podemos apreciar los siguientes planos: la realidad de una nación en guerra, la historia de una mujer común que habla con su hija y el influjo de la cultura contestataria

16 Una nación fragmentada y una cultura que irrumpe Mía Gallegos
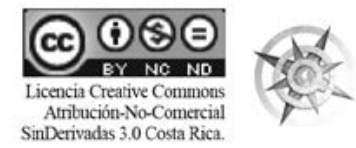
de los Estados Unidos y su presencia en el país centroamericano.

Los cines de San Salvador fueron fundamentales en mi formación. Y la película es Woodstock, que para mi generación fue una película fundacional. Los cines donde la exhibían se llenaban de cipotes fumando mariguana descaradamente. Así que era toda una experiencia alternativa y hippie ir a ver esa película, y otras que tal vez mencionaré en otras obras. Yo quería reflejar eso. Quería contar cómo era la vida cotidiana de mi generación, cuáles eran los usos amatorios de los 70 y a qué nos enfrentábamos los jóvenes en aquella época. La política, por ejemplo, que era un campo minado. (González Huguet, entrevista a la autora, julio 2015).

A propósito de este tema, Néstor García Canclini señala que:

Los estudios sobre narrativas identitarias hechas desde enfoques teóricos que toman en cuenta los procesos de hibridación, y cita a Hannerz, Hall, muestran que no es posible hablar de identidades como si solo se tratara de un conjunto de rasgos fijos, ni afirmarlos como la esencia de una etnia o una nación. (2010: pág. 17)

$Y$ es que en este sentido conviene tener presente el proceso globalizador, en este caso, en el campo de la cultura y se puede apreciar de qué manera la nación del norte y sus valores encuentran eco entre los jóvenes salvadoreños de la década de los setenta.

Esta obra es de carácter realista. La historia que se cuenta, aunque los personajes sean ficticios, es verídi$\mathrm{ca}$, ya que la guerra civil, la posible historia y sus personajes represen$\tan$ a seres humanos que sucumbieron, migraron o sobrevivieron en medio de todos estos episodios: Quería contar cómo era la vida cotidiana en aquella época. La familia es claramente disfuncional. El padre es una ausencia obvia. En ese sentido, no es nada distinta de la realidad de algunas familias concretas que conocí en mi infancia y adolescencia. (Entrevista realizada a la autora, julio 2015).

Este apego a lo que ocurre, según palabras de la autora, es lo que le otorga al monólogo una visión realista.

Sin embargo, a partir de ahora, luego de analizar en líneas muy generales este monólogo teatral, me voy a detener a formular una reflexión en torno a las dos entidades disociadas que mencioné al principio: la nación y la cultura, que como veremos discurren por distintos cauces. 
En primer término, traigo a colación un texto de Johan Rudolph Rocker, que lleva el título El Poder contra la Cultura que señala lo siguiente:

Todo poder supone alguna forma de esclavitud humana, pues la división de la sociedad en clases superiores e inferiores es una de las primeras condiciones de su existencia. La separación de los hombres en castas, estamentos y clases, que emana de toda estructura de poder, corresponde a una necesidad interna para separar del pueblo a los privilegiados, y las leyendas y tradiciones procuran alimentar y ahondar en las concepciones de los hombres la creencia en la ineludibilidad de esa separación.( 2007, pág. 1)

Aquí es necesario precisar que la historia de El Salvador está marcada por la represión, el genocidio, los golpes militares, la pobreza, la exclusión y el exilio. En la hora actual se estima que un $30 \%$ de la población tuvo que exiliarse durante la época de guerra. De ahí que, sin la menor duda, la cultura, como manifestación liberadora de los pueblos, discurre por un cauce distinto al de los poderosos y privilegiados.

Cabe añadir una oración de Johan Rudolph Rocker del texto ya citado: ...el Estado fue desde el comienzo la energía paralizadora que estuvo con manifiesta hostilidad frente al desarrollo de toda forma superior de cultura. Los Estados no crean ninguna cultura; en cambio sucumben a menudo a formas superiores de cultura. Poder y cultura, en el más profundo sentido, son contradicciones insuperables; la fuerza de la una va siempre mano a mano con la debilidad de la otra. Un poderoso aparato de Estado es el mayor obstáculo a todo desenvolvimiento cultural. Allí donde mueren los Estados o es restringido a un mínimo su poder, es donde mejor prospera la cultura. (2007: pág. 1)

El Salvador, a lo largo de su historia siempre ha estado gobernado por una oligarquía formada por catorce familias que ostentan toda clase de privilegios, quienes han puesto a los militares al mando del país.

Luego de los Acuerdos de Paz de Chapultepec en 1992, cambios de muy diversa índole han ocurrido en este país centroamericano. Entre ellos destaco que se ha logrado mantener lejos del poder a los militares. No obstante, y aun cuando en la actualidad gobierna el Frente Farabundo Martí, la estructura económica de carácter neoliberal sigue firme, pese a cambios que de manera muy pausada y paulatina han impulsado

18 Una nación fragmentada y una cultura que irrumpe Mía Gallegos
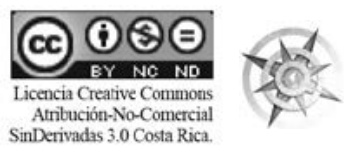
Maurico Funes y Sánchez Cerén, actual gobernante.

Según el analista Carlos Velázquez Carrillo, en el ensayo titulado La Consolidación Oligárquica Neoliberal en El Salvador y los retos para el gobierno del FMLN, las promesas de cambio fueron cosméticas:

No obstante, las promesas de cambio no fueron radicales o substanciales, y es aquí donde yace el gran reto para el gobierno del FMLN: al prometer medidas cosméticas y superficiales sin abordar la base fundamental de la desigualdad social y la pobreza, es decir el sistema oligárquico en sí, el FMLN ha asegurado la continuidad del sistema que implementó ARENA a favor de un puñado de oligarcas. Nada más que un cambio radical podría desmantelar la consolidación oligárquica neoliberal, es decir, la raíz de los problemas más básicos que el país enfrenta.(2014, s.p.)

Como podemos observar, el Estado siempre tiende a paralizar, en cambio la cultura se desborda y ese fue el proceso que cumple el monólogo teatral de Carmen González Huguet. Esta autora precisamente nos presenta ese cruento período y es importante anotar que el personaje femenino de esta obra no asume una posición política, tan solo es testigo de los acontecimientos y masacres. El hecho de que González Huguet presente a una mujer desde el filo de la vida cotidiana, lo vuelve real, verosímil, creíble. Si la hubiera dotado de una clara ideología, entonces otro muy distinto habría sido el personaje y representaría los intereses de otras capas y clases sociales.

Esta obra de la escritora salvadoreña, me obligó a realizar una relectura de la de Adolfo Sánchez Vázquez, Las Ideas Estéticas de Marx, y enfatizo la siguiente cita para hablar de la noción de literatura realista:

Cuando el artista se enfrenta a la realidad, no la toma para copiarla, sino para apropiársela, convirtiéndola en soporte de una significación humana. Apropiarse estéticamente la realidad es integrarla en un mundo humano; hacer que pierda su realidad en sí, transformarla hasta hacer de ella una realidad humanizada. Lo que en nombre del realismo se limita a copiar o a imitar lo real no es realismo ni arte. El verdadero realismo es siempre transformación de lo real creación de una nueva realidad. Y como se vale de la figura para transfigurarla, su referenciacia a lo real jamás será un muro para un verdadero creador realista. Un realismo auténtico está, por tanto, muy lejos de haber agotado, en nuestro tiempo, sus posibilidades de expresión. (1979, pág. 106). 
A lo largo de la lectura de Jimmy Hendrix toca mientras cae la lluvia, podemos ver cómo, de un lado de la realidad, está el pueblo, los sin nombre, los sin clase, los excluidos que se manifiestan con viveza mediante el uso de un idioma cotidiano y colmado de modismos y, por otro, el poder, el poder omnímodo que irrumpe y aplasta. Se puede palpar un pueblo que bulle. Y por otra parte, se intuye un poder que paraliza. En este mismo sentido y para recalcar el papel paralizante del Estado, es necesario señalar que la historia que se cuenta ocurre en el período de la guerra de los doce años y las aplastantes consecuencias que tuvieron estos hechos en la economía del país.

Y más allá, donde se anuda el imaginario, ahí donde surge el concepto de nación, en la obra se puede también apreciar que los salvadoreños desplazados, excluidos, los migrantes llevan a otras tierras sus ideales, aquellos que no pueden realizar en su tierra y la mayoría de las veces tampoco en otros lares. Es un país dividido. Siempre lo ha estado. El tejido social está roto. Pero el arte, la literatura en este caso nos presenta un mundo en el que se pueden palpar todas las contradicciones, de clase, de género, de exclusión, de marginación.
La sombra de Jimmy Hendrix se extiende. Podemos escucharlo mientras cae la lluvia. Mientras caen las balas, mientras yacen los cuerpos inertes de salvadoreños sin nombre, de prelados, de jesuitas. Mientras tanto un alto porcentaje de salvadoreños ha emigrado a los Estados Unidos, principalmente a Los Ángeles de California. Los hijos de salvadoreños nacidos allá ostentan una doble nacionalidad. También han perdido la noción de pertenencia. Los jóvenes pandilleros, las maras, hijos de salvadoreños migrantes, no encuentran arraigo en ninguna parte, ni en El Salvador ni en los Estados Unidos. Se extiende la sombra de Jimmy Hendrix. También se extiende la nacionalidad salvadoreña con todas sus contradicciones, sus heridas, sus muertos y sus quebrantos. ¿Cómo hablar de nación en estas circunstancias? Y termino con las palabras de Carmen: este no es un país.

\section{Referencias bibliográficas}

González Huguet, Carmen. (2004). Jimy Hendrix toca bajo la lluvia. San Salvador, El Salvador: Libros de Centroamérica.

García Canclini, Néstor. (2010). Culturas Híbridas. Estrategias para entrar y salir de la modernidad. Buenos Aires, Argentina: Editorial Paidós. 
Rocker, Johan Rudolf (2007). El Poder contra la Cultura. Nacionalismo y Cultura. En Biblioteca Virtual Antorcha (Chantal López y Omar Cortés Eds) Disponible en: www.antorcha.net/ biblioteca_virtual/política/nacionalismo/indice.html

Sánchez Vázquez, Adolfo. (1979). Las Ideas Estéticas de Marx. México. Ediciones Era. Recuperado de dirección web. Disponible en: diansia. filosoficas.unam.mx/index.php.contenido/n-merosanteriores $12 /$ adolfo-s-nchez-v-squez-las-ideas-estéticas-de-marx/

Velázquez Carrillo, Carlos. La Consolidación Oligárquica Neoliberal en El Salvador y los retos para el gobierno del FMLN. Recuperado de dirección web. Disponible en: www.academia. edu/827980 